\title{
Possibilidades da economia popular e solidária no Brasil contemporâneo: apontamentos
}

Possibilities of the popular and solidary economy in Brazil: notes

\begin{abstract}
This article discusses popular and solidarity economy - EPS - in Brazil. The main argument is that the conditions for a strengthening of the EPS across the public sector economy and enterprises' economy are more favorable today, due to three major movements that bring together central and peripheral countries around the debate of different forms of production: a) increasing articulation of the popular economy to the global production chains; b) politicization that occurs with the extended urbanization throughout the territory; c) growing criticism of the market society and the advancement of counter-movements in response. However, the rise of EPS, from a precarious component of global networks to a key for a plural economy, will not happen without major changes in the modes of regulation governing the daily relationships and the public policies.
\end{abstract}

\section{Keywords}

popular economy, solidarity economy, precarious labor, plural economy.

JEL Codes B55, P25, J54.
Sibelle Cornélio Diniz ${ }^{(1)}$

(1) Universidade Federal de Minas Gerais

\section{Resumo}

Este artigo discute o caráter contemporâneo da economia popular e solidária (EPS) no Brasil. $O$ argumento principal é que as condições para um fortalecimento da EPS frente à economia do setor público e à economia empresarial são mais favoráveis na atualidade, em função de três movimentos que reúnem os países centrais e periféricos em torno do debate por formas de produção distintas: a) a maior articulação das formas econômicas populares às cadeias produtivas globais; b) o processo de politização que se verifica com a expansão do tecido urbano a todo o território; c) a crítica crescente aos rumos da sociedade de mercado e o avanço dos contra movimentos em resposta. No entanto, a elevação da EPS, de componente precário das redes globais a peça fundamental de uma economia plural, não se dará sem transformações profundas nos mecanismos de regulação que regem as relações cotidianas e as políticas públicas.

\section{Palavras-chave}

economia popular, economia solidária, precarização do trabalho, economia plural.

Códigos JEL B55, P25, J54. 


\section{Introdução}

Apesar dos muitos termos e conceitos envolvidos na discussão sobre "economias diversas" (Gibson-Graham, 2008) ou "outras economias" (Cattani et al., 2009), este estudo se ampara na corrente de maior relevância entre os estudos da América Latina, que parte da peculiaridade dos processos econômicos aqui vivenciados para pensar outras maneiras de compreensão do sistema econômico e do desenvolvimento. Essa corrente surge nos anos de 1970 com a categoria economia popular (EP), ganha espaço no Brasil nos anos de 1990 a partir da noção de economia solidária (ES) e se articula internacionalmente à economia social e solidária (ESS) (Diniz, 2017). O termo "economia popular e solidária" (EPS) é utilizado, assim, para abranger um conjunto heterogêneo de práticas econômicas realizadas pelos trabalhadores a partir de sua própria força de trabalho, com o objetivo de assegurar a reprodução da vida social, muitas vezes em bases solidárias.

Este artigo discute o caráter contemporâneo da EPS no Brasil, duas décadas após suas formulações ganharem espaço nos debates internacionais. Nesse sentido, os questionamentos que orientam a elaboração do artigo são: o que importa falar de uma economia popular e solidária na contemporaneidade? Qual função ela cumpre, no todo do sistema econômico? Quais modificações se deram nessa economia nos anos recentes, com os movimentos de reconfiguração produtiva e as transformações significativas no mercado de trabalho? Sobretudo, qual papel essa economia poderia assumir, na contemporaneidade, dentro de um modo de regulação ${ }^{1}$ que a compreendesse como um componente relevante dos processos econômicos, por seu potencial de organização do trabalho em bases mais sustentáveis, inclusivas e emancipadoras?

Tendo esse ponto de partida, este estudo se baseia no conjunto de pressupostos apresentados a seguir.

Um primeiro pressuposto é o de que a economia brasileira, como outras economias latino-americanas, pode ser considerada uma "economia mista sob a dominância capitalista" (Coraggio, 2013). Isso implica dizer que outras lógicas ou princípios de comportamento econômico, além do mercado,

1 Tendo por base a escola francesa da regulação, o modo de regulação é compreendido como o conjunto de procedimentos, instituições, valores, hábitos e leis que perpassam o regime de acumulação (forma sistematizada de organização da produção, distribuição e do consumo) em uma dada sociedade (Aglietta, 1976; Boyer, 1986; Lipietz, 1988). 
caracterizam nossos processos econômicos. Para além da economia empresarial orientada para o lucro, contamos aqui com uma expressiva economia do setor público, que abrange as redes de produção e consumo em torno do Estado. E, ainda, com uma considerável economia popular, formada por unidades produtivas com uma racionalidade orientada para o trabalho, e não para o capital (Coraggio, 2003). A despeito da organização dessa sociedade em torno de uma ordem cultural capitalista (Sahlins, 2003), o conjunto das nossas relações econômicas passa notavelmente pelos princípios da reciprocidade, da domesticidade e da redistribuição (Polanyi, 2011).

Essa configuração é balizada pelos processos vivenciados no século XX, quando modernização incompleta e urbanização acelerada foram acompanhadas do acirramento das desigualdades e da não consolidação de um Estado de bem-estar social. Tal conformação garantiu espaço para as redes de solidariedade e ajuda mútua, para a economia informal, marginal e mesmo a economia ilícita. Essa economia não empresarial, que já foi tratada na literatura como "setor tradicional", "setor informal", "economia informal", entre outros termos, ganha outro lugar quando se evidencia sua racionalidade interna, orientada ao trabalho e à reprodução ampliada.

Um segundo pressuposto é o de que essa economia popular, com seu componente de solidariedade (Razeto, 1993; Coraggio, 1994, 2000), sempre existiu em nossa sociedade, como elemento estrutural e integrado às redes de produção de articulação internacional, mas teve seu papel transformado nas décadas recentes, tendo em vista as reconfigurações no mundo da produção e do trabalho. No pós-fordismo, essa economia se coloca, em diferentes graus, como componente da precarização do trabalho. Assim como ocorre nos países centrais, as redes de organização familiar e patriarcal do trabalho se integram aos processos de flexibilização e fragmentação produtivas, acompanhando os movimentos de feminização do trabalho, redução de garantias trabalhistas e queda dos ganhos reais. No Brasil, o chamado circuito inferior da economia urbana (Santos, 2008) ${ }^{2}$ se

2 Em fins da década de 1970, Milton Santos propôs uma leitura das cidades dos países subdesenvolvidos a partir de dois circuitos (ou sistemas) econômicos. O espaço desses países, ao se organizar e se reorganizar em função de interesses externos, configura-se como descontínuo, instável e multipolarizado. Cria-se assim um circuito da economia urbana altamente beneficiado pelas modernizações, e outro que só parcialmente se beneficia, ou absolutamente não se beneficia, do progresso técnico e das vantagens ligadas a ele. A origem dessa configuração estaria nos processos de industrialização e de modernização - seletiva e incompleta - do século XX, guiados por firmas multinacionais intensivas em tecnologia e geradoras de um número limitado de empregos. O circuito chamado "superior" é composto principalmente 
reconfigura em função das mudanças no nível organizacional, informacional e das finanças, movendo-se, em grande medida, em função dos movimentos do circuito superior (Silveira, 2010; 2011). Os dois circuitos parecem, no entanto, cada vez mais interdependentes, ou seja, as formas produtivas que compõem o circuito inferior são cada vez mais cruciais para o desenvolvimento e a expansão do circuito superior.

O terceiro pressuposto é que, na acumulação flexível, o trabalho assume outro lugar enquanto fator de produção e enquanto elemento constituidor de identidades (Antunes, 2005), o que redefine o papel da economia popular. A crescente "mercadificação" do trabalho abre espaço para movimentos de contestação da sociedade de mercado, orientando a criação e o fortalecimento de redes de produção e consumo alternativas. A falência do Estado de bem-estar e da crença na capacidade do mercado de abarcar o conjunto de trabalhadores e de atividades produtivas orienta novas questões e novas formas de organização. Tanto nos países centrais quanto nos periféricos, os discursos se voltam às antigas e novas formas de solidariedade econômica, no sentido de nortear mecanismos de regulação econômico-políticos que não passem apenas pelo mercado ou pelo Estado. Nessa perspectiva, a existência de uma economia popular aparece como potencialidade, na medida em que, nas formas de produção e distribuição econômica que a caracterizam, as atividades econômicas não se desvinculam das relações sociais no seu sentido mais estrito. A permanência da economia popular evidencia as redes de solidariedade existentes no cotidiano das pessoas e as revelam como um substrato importante para processos mais amplos ligados à chamada economia social e solidária.

A busca por uma produção pautada em outros objetivos, que não o lucro, e em outras relações com o trabalho e com os recursos naturais, é fortalecida ainda pelo processo de urbanização extensiva (Monte-Mór, 2015). A extensão das condições gerais de produção aos territórios implica também a politização do espaço social. Formas de organização coletivas

de atividades capital-intensivas, em grande parte imitativas, de produção em grande escala, articulada para fora da cidade e da região, e tendo como objetivo principal a acumulação de capital. É formado pelo comércio e indústria para exportação, indústria urbana moderna, comércio e serviços modernos, negócios bancários, comércio atacadista e transporte. Já o circuito "inferior" abrange as atividades de pequena dimensão, principalmente serviços não modernos abastecidos pelo comércio em pequena escala, intensivos em trabalho e com relevante potencial criativo e articulação na cidade e região. Trata-se primordialmente da pequena produção manufatureira, em grande parte artesanal, e do comércio não moderno, além das atividades domésticas. 
pautadas na colaboração e na reciprocidade ganham espaço nas novas formas urbanas, o que pode ser ilustrado pelo avanço em número e organização dos movimentos sociais em torno de pautas como a produção agroecológica, o comércio justo, a conservação ambiental, a autoconstrução etc. O maior acesso às redes de comunicação e transportes, à escolarização formal, e mesmo à proteção conferida pela legislação se tornam substratos para a organização em torno da economia social e solidária.

Assumindo tais pressupostos, o enfoque adotado é o de enfatizar a diversidade de processos econômicos existentes em nossa economia, buscando caracterizá-la como economia plural instituída, o que justifica olhares diferenciados para racionalidades econômicas, recursos e processos de formação distintos, valendo tanto para as leituras acadêmicas quanto para as definições de políticas públicas. Como economia plural instituída, considera-se uma economia que se caracteriza pela coexistência de princípios econômicos, que se complementam em graus diversos, e uma economia que não se autonomiza do social, mas se encontra, ao contrário, submetida às regras e leis definidas em cada sociedade, ou seja, um sistema econômico que é, a priori, uma construção sociopolítica (Polanyi, 2012).

Não se trata, portanto, de pensar uma economia que substitua a ação estatal - numa perspectiva filantrópica, como habitualmente se associa ao terceiro setor, ou de provisão de serviços antes afeitos aos Sistemas de Bem-Estar, como no caso da economia social institucionalizada na França. Ao contrário, é reconhecida a necessidade de articulação da economia popular solidária tanto à esfera pública quanto à esfera privada, buscando apontar a possibilidade de novas formas de regulação que permitam complementar as regulações nacionais ou suprir suas faltas (França Filho, 2001).

Nesse sentido, o artigo sugere apontamentos para uma discussão do caráter contemporâneo da EPS no Brasil. $O$ argumento principal desenvolvido é que as condições para o fortalecimento da economia popular e solidária, ou sua elevação de um conjunto de pequenas práticas descoordenadas a um sistema mais articulado e orgânico, são mais favoráveis na atualidade do que o eram quando o debate se consolidou na América Latina, em meados dos anos de 1990. Isso se dá pelas modificações no mundo do trabalho, da produção e do consumo na contemporaneidade, quais sejam, a) a crítica crescente aos rumos da sociedade de mercado e os contramovimentos em resposta; b) a maior articulação das formas populares às cadeias produtivas globais; c) o processo de politização que se verifica com a expansão do 
tecido urbano a todo o território. Mas essa elevação da economia popular, de componente precário das redes globais a componente fundamental de uma economia plural, não se dará sem transformações profundas nos mecanismos de regulação que regem as relações cotidianas e as orientações das políticas públicas.

A primeira seção discute a configuração dos circuitos superior e inferior da economia urbana no momento atual, buscando problematizar de que modo a hibridação de recursos dos dois circuitos no território apresenta possibilidades para a economia popular. A segunda seção trata dos processos de urbanização e de como a politização do tecido social que acompanha a extensão das condições gerais de produção aos territórios abre espaços para a maior articulação em torno da EPS ao expandir as sinergias possíveis entre os modos de integração econômica. Já a última seção trata do conceito de economia plural em conexão ao de desenvolvimento endógeno, considerando essas noções como chaves para a compreensão do papel da economia popular dentro de outro modo de regulação das relações econômicas.

\section{Antigas e novas relações entre os circuitos da eco- nomia urbana}

As transformações contemporâneas na produção e no trabalho têm reconfigurado a economia popular e solidária. Nesse contexto, as relações entre a EPS e o circuito superior das economias urbanas têm sido crescentemente marcadas pela interdependência.

Uma leitura atual dos processos de produção e de consumo nos países periféricos revela que os circuitos superior e inferior da economia urbana, assim chamados por Milton Santos (2008), permanecem em uma relação de subordinação. As configurações territoriais deixam claras as distinções entre os circuitos quanto a tecnologia, capacidade decisória e incentivo estatal (Silveira, 2010; 2011). ${ }^{3}$ O circuito inferior parece se subordinar ao superior através de formas múltiplas de exploração do trabalho e dos recursos naturais.

3 Análises dos circuitos da economia para realidades específicas podem ser encontrados em Bicudo Jr. (2006), Cataia e Silva (2013), Montenegro (2006), Oliveira (2008), Salvador (2011), Serpa e Porto (2007) e Trindade Jr. (2005). 
A reestruturação territorial e produtiva que se verifica nas décadas recentes é caracterizada pela extensão das condições gerais de produção a todo o território, no processo conhecido como urbanização extensiva (Monte-Mór, 2006; 2007). A expansão do tecido urbano-industrial e, consequentemente, das redes de serviços, transportes, infraestrutura e comunicações, permite integrar os mercados e a informação. Nesse sentido, os espaços periféricos, as concentrações urbanas, as áreas rurais, entre outras configurações socioespaciais, são reconfigurados. A dicotomia urbano-rural é, pelo menos virtualmente, superada, o que possibilita formas renovadas de competição e de cooperação nos territórios (Monte-Mór, 2008).

Do ponto de vista do circuito superior, esse movimento permite aumentar seu controle sobre o território, o que revela um acesso privilegiado aos bens públicos e um uso hierárquico dos bens privados. É no circuito superior que estão os motores da nova divisão internacional do trabalho, pautada na técnica, ciência, informação e finanças. O crescente uso corporativo dos territórios nacionais pelo circuito superior ocorre sob a égide do meio técnico-científico-informacional.

Trata-se de corporações globais e multissetoriais que abrangem petróleo, gás e energia, indústria automotiva, telecomunicações, mineração, siderurgia e metalurgia, comércio atacadista e varejista, e ainda bancos e seguradoras, fundos de investimento e pensão, indústrias de alta tecnologia, empresas de consultoria e outras produtoras de informação estratégica, propaganda e marketing, administração e logística, grandes importadores e exportadores, grandes grupos de entretenimento. Enfim, holdings integradas por empresas industriais, comerciais $e$ de serviços avançados (...) que necessitam de um território moderno e, portanto, exercem influência sobre as políticas. (Silveira, 2011, p. 4, tradução nossa).

Ao tempo que eleva sua influência, o circuito superior concentra os processos decisórios e de gestão em áreas menores, específicas, e se distancia das atividades "banais" da cidade. Esse circuito se robustece seletivamente nas grandes cidades e nas cidades médias, enquanto as metrópoles se reforçam como centros de produção de informação e de comando (Silveira, 2011).

Nas décadas recentes, esse circuito superior cresce, gerando poucos empregos e expandindo o consumo. A compra de insumos de países como a China, a preços baixos, permite reduzir os custos sem diminuir os preços finais. A influência sobre os meios de comunicação é um fator a corroborar a hegemonia do circuito superior, ao "desqualificar" marcas e produtos "superados" (Silveira, 2011).

Enquanto o circuito superior se distancia do inferior do ponto de vista de suas características, fomenta um conjunto de atividades pelas quais o 
capital hegemônico não se interessa a priori, ligadas ao chamado circuito superior marginal, ${ }^{4}$ que ganha espaço e se fortalece. Trata-se dos serviços produtivos e da produção de insumos intimamente ligados à técnica e organização do circuito superior (transportes, consertos, distribuição, abastecimento, contabilidade, assessoria, propaganda, produção de certos insumos). São atividades concentradas nas metrópoles e nas cidades médias onde o circuito superior avança (Silveira, 2010; 2011). ${ }^{5}$

As interdependências entre os circuitos, entretanto, parecem maiores, como evidenciam, por exemplo, as localizações de cadeias comerciais em áreas periféricas de consumo popular, antes reservadas aos pequenos capitais, o crédito agora concedido pelos grandes bancos às camadas mais empobrecidas, o uso das técnicas contemporâneas nas atividades do circuito inferior como telefonia móvel, informática, câmeras, entre outros (Silveira, 2004). Montenegro (2006) aponta ainda o crescente uso da publicidade cartões de visitas, banners, pequenos anúncios - e o acesso ao sistema bancário - uso de cheques e cartões de crédito e débito - pelo circuito inferior.

É na economia popular, e também na economia informal, que se dão os maiores avanços recentes em termos de acesso a bens e serviços, condições de moradia e níveis de escolaridade formal (Diniz, 2016). A integração da economia popular às redes de comunicação e de transportes implica também maior relação com o circuito superior. Já a inserção nas políticas públicas amplia os elos, reais e potenciais, com a economia do setor público.

Logo, a economia popular, que pode ser identificada como parte do circuito inferior, quando se trata da produção voltada aos mercados locais e pouco articulada externamente, e como parte do circuito superior marginal, quando se trata dos serviços produtivos, torna-se cada vez mais

4 Milton Santos trata o circuito superior marginal como um componente do circuito superior: "A atividade de fabricação do circuito superior divide-se em duas formas de organização. Uma é o circuito superior propriamente dito, a outra é o circuito superior marginal, constituído de formas de produção menos modernas do ponto de vista tecnológico e organizacional. O circuito superior marginal pode ser o resultado da sobrevivência de formas menos modernas de organização ou a resposta a uma demanda incapaz de suscitar atividades totalmente modernas. Essa demanda pode vir tanto de atividades modernas, como do circuito inferior. Esse circuito superior marginal tem, portanto, ao mesmo tempo um caráter residual e emergente" (Santos, 2008, p. 103).

5 O circuito superior marginal tem papel crescente nas economias urbanas, possuindo, ao mesmo tempo, um caráter residual e emergente: residual porque é o resultado da sobrevivência de formas menos modernas de organização, e emergente por ser uma resposta a demandas incapazes de alavancar atividades totalmente modernas. O circuito superior marginal é conveniente para um conjunto de firmas incapazes de arcar com os custos trabalhistas, salariais e publicitários existentes no circuito superior (Santos, 2008; Silveira, 2010; 2011). 
imbricada ao circuito superior, compartilhando com esses recursos nos territórios, integrando-se às redes organizacionais e técnicas, acompanhando a intensificação e a diversificação dos fluxos e do consumo, a expansão da publicidade e das redes de informação. Nesse sentido, a economia empresarial, a economia do setor público e a economia popular parecem cada vez mais interdependentes.

Tal integração, no entanto, não se dá sempre de forma favorável à economia popular. Os vínculos de emprego que compõem as práticas do circuito superior e de suas redes, tecidas na nova divisão internacional do trabalho, não raro revelam processos de precarização, em que o trabalhador é desprovido de garantias e de vínculos permanentes com o setor privado ou com o Estado. Nesse sentido, parte da economia popular parece ocupar as "pontas" dos processos de terceirização das cadeias produtivas globais, subordinando a produção individual e domiciliar aos processos decisórios do circuito superior, como evidenciado nos trabalhos de Leite $(2004 ; 2011)$ a partir de evidências empíricas.

Este é o caso da construção civil guiada pelos grandes grupos construtores, de capital nacional e estrangeiro, dos trabalhadores agrícolas atuantes na produção em larga escala e das operadoras de máquinas de costura que constroem, em seu domicílio de residência, peças de grandes marcas internacionais. É o caso também das ocupações que se vinculam, de certo modo, ao circuito superior marginal, como aquelas ligadas aos transportes, serviços mecânicos e distributivos, entre outras.

Por outro lado, a produção de pequeno porte, voltada ao fornecimento dos mercados locais, permanece significativa, como se verifica nos setores de serviços pessoais (embelezamento, cuidados de idosos e crianças), confecções ligadas a pequenos consertos, agricultura familiar e urbana, serviços mecânicos e transportes em menor escala, reciclagem etc. Esses setores se reconfiguram atualmente em função do maior acesso às condições gerais de produção estabelecidas no circuito superior, alterando assim seus insumos produtivos, suas formas de publicidade, seu acesso ao financiamento e sua integração às redes de comunicação.

Sendo assim, os processos contemporâneos parecem evidenciar duas práticas da economia popular: uma vinculada mais diretamente às cadeias produtivas globais, caracterizada por relações de trabalho precarizadas, postos de trabalho não raro ocupados por grupos mais vulneráveis, como as mulheres e os menos escolarizados, onde a produção é subordinada 
às grandes empresas internacionais. A outra ligada ao abastecimento de demandas locais, mas cada vez mais vinculada aos circuitos superiores, seja pelo maior uso das tecnologias, pelo acesso ampliado ao crédito, pelo maior acesso à informação possibilitado pelas redes sociais etc.

Num mesmo setor de atividade, por exemplo, o de confecções, podem-se identificar relações articuladas diretamente ao grande capital, como no caso das costureiras que atuam por conta própria na produção de peças para grandes marcas internacionais, e relações voltadas aos mercados imediatos, como a produção de vestuário em pequena escala, comercializada em feiras ou no comércio local, e os pequenos consertos.

Cabe pensar, então, a economia popular como parte fundamental do sistema econômico, seja no caso do trabalho terceirizado, em que os custos da mão de obra são reduzidos pelas relações de trabalho mais flexíveis e sem garantias formais, seja nos circuitos de produção em nível local, que garantem parte da demanda pelos produtos e serviços do circuito superior. Em ambos os casos, a economia popular aparece como peça fundamental no suprimento de novas e antigas demandas, tanto aquelas colocadas pela produção ligada às redes capitalistas de grande alcance, quanto aquelas locais, de menor escala, não supridas por essas redes.

Essa maior interdependência entre os circuitos da economia urbana, ou a crescente articulação entre as formas econômicas populares e as cadeias produtivas globalizadas, abre espaços diversos à economia popular solidária. Nesse sentido, cabe pensar formas de cooperação que deem conta dessa inter-relação e, ao mesmo tempo, do aproveitamento das potencialidades da economia popular, como o repasse do conhecimento tradicional e as práticas solidárias presentes nessas iniciativas.

Diagnósticos das distintas configurações dos circuitos nos territórios se fazem necessários para a construção de novos mecanismos de regulação, tanto no sentido de barrar ou colocar limites à "mercadificação" dos recursos naturais e do trabalho, quanto de induzir formas de integração pautadas nas possíveis complementaridades, como processos de formação e de compartilhamento de conhecimentos com ganhos mútuos, fornecimento de insumos em bases sustentáveis, compartilhamento de espaços físicos etc. Deve-se considerar, ainda, o potencial de articulação com as redes de produção e de consumo que conformam a economia do setor público, por meio, por exemplo, da compra pública da produção popular solidária e dos processos de formação e de financiamento. 
Nesse sentido, abrem-se possibilidades diversas para estudos setoriais voltados à produção de pequeno porte, de base popular e solidária, e que enfatizem os vínculos dessa produção ao setor público e à economia empresarial, subsidiando ações voltadas ao desenvolvimento territorial com base na articulação entre os princípios de comportamento econômico. ${ }^{6}$

Em suma, ao colocar luz sobre as relações diversas entre a EPS e as demais esferas da ação econômica, seria possível fortalecer as potencialidades de uma economia marcada pela pluralidade de processos econômicos. Voltaremos a esse assunto na última seção do artigo.

\section{Urbanização extensiva e a práxis compartilhada}

A diversidade de formas espaciais e de articulações possibilitada pela acumulação flexível e pelos processos contemporâneos de urbanização abre espaços à economia popular e solidária.

Com a globalização amplia-se a variedade de tipos econômicos, culturais, religiosos e linguísticos, multiplicam-se os modelos produtivos, de circulação e de consumo, segundo qualificações e quantidades, e também aumenta a variedade de situações territoriais. Na realidade, tais situações se submetem a constantes mutaçôes e encobrem uma rica, variada e sempre renovada divisão do trabalho e divisão territorial do trabalho. Nessas condições, a metrópole está sempre se refazendo: na forma, na função, no dinamismo e no sentido. Essa riqueza do inesperado constitui a possibilidade de construção de novos futuros. (Santos; Silveira, 2001, p. 287).

Como aponta Arroyo (2008), a multiplicidade de práticas do circuito inferior agrega dinamismo à economia e à vida urbana. Essas práticas, ligadas ao dia a dia, ao cotidiano, criam uma pluralidade de expressões e de códigos, diversidade esta que expõe a tensão e o conflito, mas que define a força das cidades. Na contemporaneidade, a coexistência dos circuitos econômicos nos territórios implica espaço que é ao mesmo tempo dividido e compartilhado, cindido e marcado pela convivência:

Mas essa desigualdade estrutural da cidade - que, aliás, é o que permite continuar asseverando a existência de dois circuitos da economia urbana - é também funcional porque, no presente, as divisões territoriais do trabalho são obrigadas a compartilhar o mesmo pedaço do território. A cidade é o reino da práxis compar-

6 De forma indireta, Abramovay et al. (2003) e Sachs (2004) discutem esse ponto para o empreendedorismo de pequeno porte no Brasil, enfatizando a produção agrícola familiar. Outros trabalhos ligados ao desenvolvimento local, arranjos produtivos locais e tecnologias sociais também poderiam ser citados. 
tida ou, em outras palavras, a manifestação mais visível do acontecer solidário, isto é, a realização compulsória de tarefas comuns mesmo que o projeto não seja comum (Santos, 1996). Poderíamos dizer que o espaço urbano é dividido mas, ao mesmo tempo, compartilhado. É nesse contexto que a cidadania poderia ser discutida nos seus verdadeiros limites e possibilidades históricas (Silveira, 2010, p. 10).

Monte-Mór (2006; 2007), com base em Lefebvre (1969, 1999), identifica nos processos de urbanização contemporâneos a ampliação das possibilidades de exercício da cidadania. Ao tempo que o tecido urbano-industrial se expande, estendem-se também o consumo pessoal e coletivo e a politização do espaço social. Essa conformação dá origem ao "urbano":

(...) sintese da dicotomia cidade-campo, um terceiro elemento na oposição dialética cidade-campo, a manifestação material e sócio-espacial da sociedade urbano-industrial contemporânea estendida, virtualmente, por todo o espaço social. (Monte-Mór, 2007, p. 7)

A urbanização extensiva, ou a extensão das condições gerais de produção (sistemas de transportes e comunicações, acesso aos serviços, legislação etc.) e das formas de vida urbanas a todo o território, conteria, em si, o germe do "urbano-utopia" lefebvriano, compreendido como a superação do urbano-industrial ao privilegiar a coletividade, a solidariedade, a complementaridade e a diversidade (Monte-Mór, 2015).

Finalmente, cumpre ressaltar que o processo de extensão da urbanização a (virtualmente) todo o espaço social carrega consigo também a extensão da pólis, da política, a recantos antes imaginados infensos à integração sócio-espacial contemporânea. De fato, a repolitização que marcou as grandes cidades nos anos $1970 \mathrm{em}$ todo o mundo e deu origem aos movimentos sociais urbanos, já muito descritos e incorporados ao planejamento e gestão urbanas, é ora (re)vistos em sua versão que integra populações rurais, até aquelas mais isoladas e distantes da dinâmica capitalista mundial, como os chamados "povos das florestas". No novo contexto da urbanização extensiva, não apenas bóias-frias, trabalhadores rurais e pequenos agricultores se integram à dinâmica urbano-(pós)industrial contemporânea, mas também indios, seringueiros, garimpeiros e outros grupos antes excluidos das sociedades modernas se organizam em formas politico-associativas várias visando garantir melhores condições de reprodução aos seus membros. (Monte-Mór, 2008, p.15)

A partir do urbano, portanto, os diversos grupos sociais organizam suas demandas e se recolocam nos processos decisórios, ampliando suas redes de organização e suas capacidades de reivindicação. Do ponto de vista da EPS, seria possível ver, no urbano, o lugar para a expressão e o resgate de princípios de comportamento econômico distintos do mercado, como a reciprocidade e a domesticidade, cuja relação pode ser ampliada, no sentido da (re)criação de formas e processos socioespaciais compatíveis com a emancipação (Monte-Mór, 2015). O urbano seria o lócus privilegiado para 
a concepção e a construção de economias plurais, em que esses outros princípios aparecem em relação de complementaridade com o mercado.

A práxis urbana, e a consequente sinergia que ela possibilita, fomenta processos inventivos e inovativos, ou seja, a criação de novas soluções para os problemas percebidos, sejam eles novos ou antigos (Jacobs, 1969). O "burburinho" das cidades, ou o contato face a face, favorece a transmissão do conhecimento tácito e a produção de sinergias no sentido da inovação e da criatividade (Storper; Venables, 2005). Embora tais processos sejam associados, em geral, às economias de aglomeração encontradas nas grandes cidades, se a tendência contemporânea é de extensão das condições urbanas a todo o território, pode-se pensar o urbano, e não as metrópoles, como lugar privilegiado da inovação econômica e social, ou de uma práxis socioespacial emancipatória.

Nessa configuração, o local e o cotidiano aparecem como lócus privilegiado da reprodução social e como instâncias prioritárias para o surgimento do "novo".

É no nivel local que, a despeito mesmo de uma subordinação estrutural ao espaço abstrato globalizado, o espaço social (re)politizado manifesta de forma mais evidente e expressiva as exigências da reprodução e as determinações imediatas da vida quotidiana comunitária. Ali, o urbano, enquanto espaço privilegiado da reprodução, se impõe muitas vezes sobre as demandas do capital e da produção industrial, matizando-as e criando mediações que podem redefinir, mesmo que parcial e subsidiariamente, a dinâmica sócio-espacial, politica e econômica local. (Monte-Mór, 2008, p. 5)

A economia popular solidária volta-se prioritariamente às demandas locais, sendo originada nas redes de cuidado e de solidariedade que se estabelecem no cotidiano. São ocupações diversas que têm sua demanda elevada nos anos recentes, como os cuidados de crianças e idosos, o artesanato, a produção de alimentos, a reciclagem, a agricultura orgânica e agroecológica, entre diversas outras. A produção é realizada nos próprios domicílios, em boa parte dos casos, e comercializada nas casas, em barracas e quiosques, nas ruas ou em pequenos comércios. A economia popular é também a economia da rua, da praça, do bairro e da vida urbana.

Enquanto prática predominantemente local e coletiva, a EPS é, em boa parte dos casos, baseada nos princípios econômicos da domesticidade e da reciprocidade, organizada no âmbito da família e em torno dos recursos do domicílio, permitindo o repasse intergeracional de conhecimentos. Acontecendo dentro do próprio domicílio ou nos espaços públicos, aproveita-se das potencialidades do trabalho feminino e invoca as sociabilidades. 
A EPS acontece de forma mais significativa nas regiões mais pobres do país, nos municípios de pequeno porte e nas áreas rurais. A integração dessas áreas periféricas, nos processos de urbanização extensiva, abre possibilidades diversas para a EPS, relacionadas à articulação entre os modos de organização econômica em bases inovadoras.

Além disso, foram significativos os avanços vivenciados pelos trabalhadores da economia popular, neste século, em termos de escolaridade, acesso a serviços ligados amoradia e presença de bens de consumo no domicílio (Diniz, 2016). Essa melhora absoluta das condições de reprodução deve se refletir nas condições de trabalho, uma vez que se assume que a produção se dá em torno da família e dos bens de consumo da família. Em especial, a presença de energia elétrica, linha telefônica e de bens de consumo como microcomputador e geladeira influenciam diretamente o trabalho no próprio domicílio.

Nesse sentido, os ganhos ligados a essa expansão do consumo pessoal e coletivo e da integração às redes de informação, comunicação, e mesmo as redes de transporte, permitem avanços no sentido de incremento dos processos produtivos e de ampliação de redes de contatos e de espaços de aprendizado coletivo.

Como demonstram os estudos de caso, alguns dos maiores ganhos da organização solidária estão na produção de novas sociabilidades, a partir das quais setores vulneráveis encontram formas de constituição de identidades e de inserção nas políticas públicas (Leite, 2009; Gaiger, 1995; Motta, 2010). Ainda que os empreendimentos encontrem dificuldades diversas para sua manutenção no tempo, aferição de resultados econômicos positivos, remuneração dos trabalhadores/sócios, comercialização dos produtos etc., não são raros os casos em que os envolvidos permanecem na atividade por encontrar ali um espaço de socialização, a possibilidade de trabalhar fora de esquemas rígidos, e, no caso da economia solidária, a possibilidade de participar ativamente em processos de transformação social.

Além disso, são inegáveis os avanços organizativos do ponto de vista dos movimentos em torno da economia solidária, comércio justo, moedas sociais, agroecologia, agricultura urbana, autoconstrução, coletivos culturais, consumo sustentável etc. ${ }^{7}$ Nas décadas recentes, esses grupos crestuições (Acesso em: 26 fev. 2018). O site do Fórum Brasileiro de Economia Solidária remete a cerca de 160 Fóruns municipais, microrregionais e estaduais, 3000 empreendimentos de eco- 
ceram em alcance e capacidade de mobilização e ganharam espaço nas políticas públicas e nos debates acadêmicos.

Em tempos de cooptação das subjetividades pelos processos de trabalho e da carência de reflexões desalienadas sobre os processos produtivos e tecnológicos, a economia popular solidária representa possibilidades de transformação ao se observarem as relações de trabalho ali constituídas e as relações estabelecidas com os recursos, naturais e construídos. Na contratendência do processo de "mercadificação" do trabalho, as bases da EPS podem conter força para a criação e o fortalecimento de redes de produção e consumo alternativas, de grande alcance. Nesse contexto, as áreas periféricas, onde se concentra a economia popular solidária, aparecem como locais privilegiados.

Os avanços vivenciados em torno da economia solidária no Brasil nas décadas recentes, do ponto de vista de mobilização de atores e diálogo com os poderes públicos, constituem uma importante base para discussões e intervenções futuras. A incorporação da dimensão urbana da EPS e das possibilidades estabelecidas pelas sinergias urbanas emerge como ponto fundamental a ser incorporado no debate.

\section{Pluralidades, territórios e desenvolvimento endógeno}

Se o contexto de expansão da economia popular e solidária é o de uma crise societária generalizada - crise de um modo de acumulação, crise do trabalho assalariado, crise ambiental e crise social -, essas experiências carregam consigo um conjunto de potencialidades e de limites, uma vez que reúnem o velho e o novo, o risco e a possibilidade, como trata Leite (2009). Sendo assim, cabe pensá-las como "espaços de fronteira", capazes de fomentar tipos distintos de sociabilidade e de subjetividade (Sousa-Santos, 2008). Não é possível, no entanto, negar sua dimensão de precariedade e de possibilidade iminente de desaparecimento ou cooptação.

Com base na discussão apresentada até aqui, pode-se dizer que a economia popular e solidária no Brasil contém atualmente elementos tanto de precarização quanto de autonomia. Precarização porque permanece, em boa parte dos casos, a situação de instabilidade de renda, dificuldades de 
estabilização dos negócios, ausência de proteção trabalhista, entre outros. Autonomia porque, apesar da inserção crescente nos processos econômicos e políticos, essa inserção se dá de forma limitada, já que as formas de regulação existentes apontam, de forma majoritária, na direção oposta. A regulação vigente, tanto no que diz respeito às ações do Estado quanto aos padrões de consumo e de produção é, no geral, limitadora do avanço da economia popular solidária. Isso acontece a despeito de essa economia ter se mostrado historicamente relevante em proporcionar a reprodução de famílias para as quais os mecanismos de regulação econômico-políticos da sociedade nunca funcionaram, quais sejam, o Estado de bem-estar social e as relações de trabalho com base no assalariamento.

Dito de outro modo, embora o nosso regime de acumulação dependa da economia popular, e sempre tenha dependido, o modo de regulação vigente só "enxerga", ou enxerga prioritariamente, a economia empresarial dita capitalista. Ainda quando o circuito inferior da economia ou a economia popular são reconhecidos nos discursos acadêmicos e governamentais, eles são frequentemente assumidos como formas temporárias para o trabalho nos moldes da empresa típica capitalista. A economia solidária, cujo reconhecimento é mais significativo no país, é ainda associada a um movimento efêmero e marginal.

Recorrendo à noção de desenvolvimento pensada por Furtado em suas obras sobre cultura e criatividade (1978; 1984; 2012), pode-se pensar em que medida nossa leitura sobre os nossos processos econômicos se orienta por forças exógenas, que impedem que enxerguemos as configurações reais dos territórios, em sua complexidade e também em sua força e potencialidade.

Furtado compreende a cultura como um sistema recorrentemente modificado pela introdução de inovações. $\bigcirc$ conceito de desenvolvimento, em Furtado, relaciona-se a dois processos de criatividade: o primeiro diz respeito à inovação técnica - ao progresso técnico e à acumulação (cultura material), enquanto o segundo trata da inovação de ideias e dos valores da sociedade (cultura não material). A invenção no âmbito da cultura não material é a responsável pelo real desenvolvimento (Furtado, 1980).

Para Furtado (1984), mais do que transformação, o desenvolvimento trata de invenção. Trata de colocar a criatividade a serviço de um projeto de transformação social com o qual se identificam os membros de uma coletividade. $O$ desenvolvimento se efetiva, então, quando a capacidade 
criativa do homem se volta para a descoberta dele mesmo, buscando enriquecer seu sistema de valores, e difundindo os valores criados aos segmentos da coletividade.

Um desenvolvimento endógeno consiste na ordenação do processo acumulativo em função de prioridades definidas pela própria comunidade em questão. Nesse sentido, uma "endogeneização do desenvolvimento" requer estruturas sociais que abram espaço à criatividade num amplo horizonte cultural.

Na visão de Furtado, o modo como se deu o desenvolvimento da periferia latino-americana impediu a consolidação e expansão de uma identidade cultural própria, impossibilitando as mudanças necessárias ao desenvolvimento. A imitação do consumo, nessa sociedade, não significa apenas uma adesão aos "valores materiais", mas implica, na verdade, que o estrangeiro passa a ser associado ao prestígio social. A penetração de ideias e valores próprios do centro condiciona negativamente o plano político, uma vez que compromete as identidades locais e as oportunidades de consolidá-las e expandi-las.

O autor cunha ainda o conceito de dependência cultural, defendendo que a dimensão cultural do fenômeno da dependência prevalece sobre as outras dimensões, como a tecnológica. A imitação das pautas de consumo dos centros, a apreciação do estrangeiro e a penetração de ideias e valores estrangeiros são elementos da desarticulação das identidades culturais na periferia. Essa dependência impede a construção de vias de conciliação entre interesses internos e externos, por meio de uma inserção internacional distinta. Ainda, dificulta a criação de soluções originais à inadequação das tecnologias geradas nos centros. Ambas as dificuldades reiteram o problema da superoferta de mão de obra e da heterogeneidade social (Furtado, 1978; Rodríguez, 2009). A superação da dependência cultural passa então pelo relacionamento com as bases culturais do passado e com os grupos excluídos dos padrões de consumo e de vida criados nos países centrais, e que puderam, assim, reproduzir e manter suas raízes culturais.

As formas econômicas populares e solidárias, em sua heterogeneidade, complexidade, e, sobretudo, na herança cultural que carregam, aparecem como um campo fecundo de investigação e de pesquisa na busca por esse objetivo. Além disso, o recente crescimento da demanda pela produção artesanal e pela produção artística abre portas para pautas de produção e de consumo mais afeitas às nossas bases culturais. 
Um avanço no sentido do desenvolvimento endógeno não se dará sem uma leitura do sistema econômico mais coerente com as diversidades de comportamento econômico existentes no Brasil. O que este artigo procurou demonstrar é que nossa economia deve ser compreendida como economia plural instituída: uma economia que se caracteriza pela coexistência de princípios econômicos, que se complementam em graus diversos, e uma economia que não se autonomiza do social, mas se encontra, ao contrário, submetida às regras e leis definidas em cada sociedade, ou seja, um sistema econômico que é, a priori, uma construção sociopolítica (Polanyi, 2012).

Procurou-se defender, ainda, que as condições para o fortalecimento da economia popular e solidária são mais favoráveis na atualidade, tendo em vista os processos de politização possibilitados pela vida urbana estendida, a maior conexão das formas populares às redes globais e o crescente questionamento da sociedade de mercado. Mas esse fortalecimento não ocorrerá sem transformações profundas nos mecanismos de regulação político-econômicos em torno dos quais se estabelecem as relações econômicas.

Se as condições são, portanto, favoráveis, e se o horizonte da transformação é o da economia plural (Laville, 2009) e o da economia do trabalho (Coraggio, 2009a, 2009b), parece que a pauta deve passar: a) por um reconhecimento da economia popular como parte relevante de nossos processos sociais e econômicos; b) por uma discussão das possibilidades efetivas de melhorias das suas condições produtivas, e que se pautem em formas endógenas de produção de conhecimento e de solução das necessidades; c) pelo reconhecimento e fortalecimento das redes e das relações com a economia empresarial e com a economia do setor público, em bases não exploratórias.

A compreensão do sistema econômico como plural (Laville, 2009) e instituído (Polanyi, 2012) parece uma chave para a proposição de mecanismos de regulação mais próximos do cotidiano atual e desejado. Nesse sentido, faz-se necessária melhor compreensão não apenas dos mecanismos internos da economia popular e solidária, mas sobretudo das suas relações, complementaridades e subordinações à economia do setor público e à economia empresarial capitalista, em suas nuances regionais.

Nesse sentido, a inserção social da economia emerge como um pressuposto básico de análise, seja no sentido de Granovetter (1985), para quem o funcionamento dos mercados só é possível a partir de sua inserção nas relações sociais, seja no sentido de Mauss (2003), para quem o dom, en- 
quanto fato social total, explicita a relevância da reciprocidade e dos vínculos sociais inclusive dentro da economia de mercado. A concepção de uma economia plural estabelece que as realizações econômicas no território não se dão apenas em torno das relações mercantis monetizadas, mas sim de uma amplitude de lógicas e de recursos que se combinam de formas diversas, envolvendo o Estado, o mercado e a sociedade civil. Nesse sentido, a economia dos territórios se apoia em grande medida na cooperação, na reciprocidade e na confiança ${ }^{8}$. Tal complexidade, que não cabe nas análises econômicas convencionais, seria a base para uma releitura dos nossos mecanismos de regulação.

Em suma, tanto em termos de recursos mobilizados (recursos mercantis e não mercantis ou não monetários) quanto das lógicas de ação, das modalidades de coordenação e dos modos de regulação, sem esquecer a relação com o território, a economia no seu conjunto (ou seja, incluindo a capitalista) não é apenas social, mas também plural (Lévesque, 2009, p. 33).

Como aponta Lévesque (2009), a economia social e solidária constitui o setor econômico mais bem equipado institucionalmente para estabelecer a hibridação de recursos e um compromisso entre as diferentes lógicas de ação no âmbito de uma economia plural, devido a sua vinculação com a propriedade coletiva, sua finalidade social e sua governança democrática. No entanto, o caminho dessa construção não é óbvio, natural e nem previamente estabelecido.

A atenção à experiência e ao cotidiano das práticas populares e solidárias, e, sobretudo, aos seus vínculos com a economia empresarial e com a economia do setor público, é um ponto de partida para a compreensão da hibridação de princípios econômicos existentes na economia brasileira e das possibilidades de desenvolvimento abertas por tal configuração.

\section{Referências}

ABRAMOVAY, R. et al. Mercados do empreendedorismo de pequeno porte no Brasil. In: COMISSÃO ECONÔMICA PARA A AMÉRICA LATINA E O CARIBE. Pobreza e Mercados no Brasil: uma Análise de Iniciativas de Políticas Públicas. Brasília: CEPAL/Escritório no Brasil/DFID, 2003, p. 233-311.

8 Desse ponto de vista, nem mesmo as empresas devem ser compreendidas como agentes voltados unicamente aos recursos mercantis, mas sim como entidades que buscam, também, forjar vínculos de natureza mercantil e não mercantil com os diversos atores que são capazes de influenciar a dinâmica territorial (Lévesque, 2009). 
AGLIETTA, M. Régulation et crises du capitalisme. Paris: Calmann-Levy, 1976.

ANTUNES, R. O caracol e sua concha: ensaios sobre a nova morfologia do trabalho. São Paulo: Boitempo, 2005.

ARROYO, M. M. A economia invisível dos pequenos. Le Monde Diplomatique, ano 2, p. 30-31, out. 2008.

BICUDO JUNIOR, E. C. O circuito superior marginal: produção de medicamentos e o território brasileiro. 2006. Dissertação (Mestrado em Geografia) - Departamento de Geografia, Universidade de São Paulo, São Paulo, 2002.

BOYER, R. La théorie de la régulation: une analyse critique. Paris: La Découverte, 1986.

CATAIA, M.; SILVA, S. C. Considerações sobre a teoria dos dois circuitos da economia urbana na atualidade. Boletim Campineiro de Geografia, v. 3, n. 1, p.55-75, jan./abr. 2013.

CATTANI, A. D.; LAVILLE, J. L.; GAIGER, L. I.; HESPANHA, P. Dicionário internacional da outra economia. São Paulo: Almedina Brasil, 2009.

CORAGGIO, J. L. Economía urbana: la perspectiva popular. Quito: Instituto Fronesis, 1994.

CORAGGIO, J. L. Da economia dos setores populares à economia do trabalho. In: KRAYCHETE, G. et al. (Org.). Economia dos setores populares: entre a realidade e a utopia, Petrópolis: Vozes, 2000. p. 91-133.

CORAGGIO, J. L. Qué significa pasar de la economía popular a la economía del trabajo? Proposta, n. 98, p. 12-20, set./nov. 2003.

CORAGGIO, J. L. Economia do trabalho. In: CATTANI, A. D.; LAVILLE, J. L.; GAIGER, L. I.; HESPANHA, P. Dicionário internacional da outra economia. São Paulo: Almedina Brasil, 2009a.

CORAGGIO, J. L. Territorio y economias alternativas. Trabalho apresentado no I Seminario Internacional Planificación Regional para el Desarrollo Nacional. Visiones, desafíos y propuestas, La Paz, $2009 b$.

CORAGGIO, J. L. Las tres corrientes de pensamiento y acción dentro del campo de la economía social y solidaria. Revista Brasileira de Estudos Urbanos e Regionais, v. 15, n. 2, p. 11-24, nov. 2013.

DINIZ, S. C. Do precário ao plural: realidades e possibilidades da economia popular no Brasil contemporâneo. Tese (Doutorado em Economia) - Centro de Desenvolvimento e Planejamento Regional, Universidade Federal de Minas Gerais, Belo Horizonte, 2016.

DINIZ, S. C. Economia Popular e Economia Social Solidária: do precário ao plural. In: XVII ENCONTRO NACIONAL DA ASSOCIAÇÃO NACIONAL DE PÓS-GRADUAÇÃO E PESQUISA EM PLANEJAMENTO URBANO E REGIONAL, 2017. Anais... São Paulo: XVII ENANPUR, 2017.

FRANÇA FILHO, G. C. de. A problemática da economia solidária: uma perspectiva internacional. Sociedade e Estado, v. 16, n. 1-2, p. 245-275, dez. 2001.

FURTADO, C. Criatividade e dependência na civilização industrial. Rio de Janeiro: Paz e Terra, 1978.

FURTADO, C. Cultura e desenvolvimento em época de crise. Rio de Janeiro: Paz e Terra, 1984.

FURTADO, C. Pequena introdução ao desenvolvimento: um enfoque interdisciplinar. São Paulo: Companhia Editora Nacional, 1980. 
FURTADO, R. F. A. (Org.). Arquivos Celso Furtado n 5: ensaios sobre cultura e o Ministério da Cultura. Rio de Janeiro: Contraponto, 2012.

GAIGER, L. I. G. As microexperiências populares: novas malhas de um tecido social? Tempo e Presença, ano 17, n. 282, p. 11-13, jul./ago. 1995.

GIBSON-GRAHAM, J. K. Diverse Economies: Performative Practices for 'Other Worlds'. Progress in Human Geography, v. 32, n. 5, p. 613-632, out. 2008.

GRANOVETTER, M. Economic Action and Social Structure: The Problem of Embeddedness. American Journal of Sociology, v. 91, n. 9, p. 481-510, nov. 1985.

JACOBS, J. The Economy of Cities. New York: Random House, 1969.

KRAYCHETE, G. et al. (Org.). Economia dos setores populares: entre a realidade e a utopia. Petrópolis: Vozes, 2000.

LAVILLE, J. L. Economia Plural. In: CATTANI, A. D.; LAVILLE, J. L.; GAIGER, L. I.; HESPANHA, P. Dicionário internacional da outra economia. São Paulo: Almedina Brasil, 2009.

LEFEBVRE, H. O direito à cidade. São Paulo: Editora Documentos, 1969.

LEFEBVRE, H. A revolução urbana. Belo Horizonte: Editora UFMG, 1999.

LEITE, M. P. Tecendo a precarização: trabalho a domicílio e estratégias sindicais na indústria de confecção em São Paulo. Trabalho, educação e saúde, v.2, n.1, p.57-94, mar. 2004.

LEITE, M. P. A economia solidária e o trabalho associativo: teorias e realidades. Revista Brasileira de Ciências Sociais, v. 24, n. 69, p. 31-51, fev. 2009.

LEITE, M. P. El trabajo en el Brasil de los años 2000: dos caras de un mismo proceso. Revista de Trabajo, ano 7, n. 9, p. 115-129, jan./jul. 2011.

LÉVESQUE, B. Economia plural e desenvolvimento territorial na perspectiva do desenvolvimento sustentável: elementos teóricos de sociologia econômica e de socioeconomia. Politica e Sociedade, n. 14, p. 107-144, abr. 2009.

LIPIETZ, A. Miragens e milagres: problemas da industrialização no terceiro mundo. São Paulo: Nobel, 1988.

MAUSS, M. Sociologia e antropologia. São Paulo: Cosac Naify, 2003. p. 183-314. Segunda parte. Ensaio sobre a dádiva: forma e razão da troca nas sociedades arcaicas. MONTE-MÓR, R. L. M. Cidade e campo, Urbano e rural: o substantivo e o adjetivo. In: FELDMAN, S.; FERNANDES, A. (Org.). O urbano e o regional no Brasil contemporâneo: mutações, tensões, desafios. Salvador: EDUFBA, 2007, p. 93-114.

MONTE-MÓR, R. L. M. O que é o urbano, no mundo contemporâneo. Textos para discussão UFMG/Cedeplar, n.281, 2006.

MONTE-MÓR, R. L. M. Cidade e campo, Urbano e rural: o substantivo e o adjetivo. In: FELDMAN, S.; FERNANDES, A. (Org.). O urbano e o regional no Brasil contemporâneo: mutações, tensões, desafios. Salvador: EDUFBA, 2007, p. 93-114.

MONTE-MÓR, R. L. M. Urbanização extensiva e economia dos setores populares. In: OLIVEIRA, M. P. et al. (Org.). O Brasil, a América Latina e o mundo: espacialidades contemporâneas. Rio de Janeiro: Lamparina/Faperj/Anpege, 2008, p. 128-140. v. 2.

MONTE-MÓR, R. L. M. Urbanização, sustentabilidade, desenvolvimento: complexidades e diversidades contemporâneas na produção do espaço urbano. In: COSTA, G. M.; COSTA, 
H. S. M.; MONTE-MÓR, R. L. (Org.). Teorias e práticas urbanas: condições para a sociedade urbana. Belo Horizonte: C/ Arte, 2015.

MONTENEGRO, M. R. O circuito inferior da economia urbana na cidade de São Paulo no período da globalização. 2006. 205 f. Dissertação (Mestrado em Geografia Humana) - Faculdade de Filosofia, Letras e Ciências Humanas, Universidade de São Paulo, São Paulo, 2006.

MOTTA, E. S. M. G. Trajetórias e transformações no mundo da economia solidária. 2010. 208 f. Tese (Doutorado em Antropologia Social) - Museu Nacional, Universidade Federal do Rio de Janeiro, Rio de Janeiro, 2010.

OLIVEIRA, E. L. Algumas considerações sobre o conceito de setor informal e a teoria dos circuitos da economia urbana. Geografias, v. 4, n. 1, p. 54-70, jan./jun. 2008.

POLANYI, K. A grande transformação: as origens da nossa época. 2. ed. Rio de Janeiro: Elsevier, 2011.

POLANYI, K. A subsistência do homem: e ensaios correlatos. Rio de Janeiro: Contraponto, 2012.

RAZETO, L. De la economía popular a la economía de solidaridad en un proyecto de desarrollo alternativo. Ciudad de México: Instituto Mexicano de Doctrina Social Cristiana, 1993.

RODRÍGUEZ, O. O estruturalismo latino-americano. Rio de Janeiro: Civilização Brasileira, 2009.

SACHS, I. Inclusão social pelo trabalho decente: oportunidades, obstáculos, políticas públicas. Estudos Avançados, v. 18, n. 51, p. 23-49, maio./ago. 2004.

SAHLINS, M. Cultura e razão prática. Rio de Janeiro: Zahar, 2003.

SALVADOR, D. S. C. de O. A expansão e a redefinição do circuito inferior da economia urbana da cidade dos países subdesenvolvidos no período atual. In: SIMPÓSIO NACIONAL DE GEOGRAFIA URBANA, 12, 2001, Belo Horizonte. Anais... Belo Horizonte: SIMPURB, 2011.

SANTOS, M. A natureza do espaço: técnica e tempo. Razão e emoção. São Paulo: Hucitec, 1996.

SANTOS, M. O espaço dividido: os dois circuitos da economia urbana dos países subdesenvolvidos. 2. ed. São Paulo: EDUSP, 2008.

SANTOS, M.; SILVEIRA, M. L. O Brasil: território e sociedade no início do século XXI. Rio de Janeiro: Record, 2001.

SERPA, A.; PORTO, G. C. S. Circuito Inferior da economia urbana: o contexto das feiras livres de Itapetinga (BA) e arredores. In: SIMPÓSIO NACIONAL DE GEOGRAFIA URBANA, 10, 2007. Anais... Florianópolis: SIMPURB, 2007.

SILVEIRA, M. L. Globalización y circuitos de la economia urbana en ciudades brasileñas. Cuadernos del Cendes, ano 21, n. 57, p. 1-21, set./dez. 2004.

SILVEIRA, M. L. Da pobreza estrutural à resistência: pensando os circuitos da economia urbana. In: ENCONTRO NACIONAL DOS GEÓGRAFOS, 16, Porto Alegre. Anais... Porto Alegre: Associação dos Geógrafos Brasileiros (AGB), 2010.

SILVEIRA, M. L. Urbanización latinoamericana y circuitos de la economía urbana. Revista Geografica de America Central, v. 2, n. 47E, p. 1-17, 2011.

SOUSA-SANTOS, B. de. Um discurso sobre as ciências. 5. ed. São Paulo: Cortez, 2008. 
STORPER, M.; VENABLES, A. J. O burburinho: a força econômica da cidade. In: DINIZ, C. C.; LEMOS, M. Economia e território. Belo Horizonte: UFMG, 2005, p. 21-56.

TRINDADE JR., S. C. Entre o público e o privado: agentes de apropriação do espaço na orla fluvial de Belém-Pará (Brasil). Scripta Nova, v. 9, n. 194, ago. 2005.

\section{Sobre a autora}

Sibelle Cornélio Diniz - sibelled@cedeplar.ufmg.br

Professora adjunta, Centro de Desenvolvimento e Planejamento Regional, Universidade Federal de Minas Gerais, Belo Horizonte, Minas Gerais, Brasil.

ORCID: https://orcid.org/0000-0002-3183-3588.

\section{Sobre 0 artigo}

Recebido em 26 de fevereiro de 2018. Aprovado em 19 de janeiro de 2019. 